\title{
Forceps Injury
}

National Cancer Institute

\section{Source}

National Cancer Institute. Forceps Injury. NCI Thesaurus. Code C116820.

Birth injury sustained during a forceps-assisted delivery. 